\title{
A SUBVERSÃO DE PAPÉIS DE GÊNERO EM EFÉSIOS: UMA ANÁLISE CO-TEXTUAL E CONTEXTUAL DE EFÉSIOS 5:18-33
}

\author{
Natan Behrendt de Carvalho*
}

\section{RESUMO}

O capítulo cinco de Efésios apresenta uma das mais difíceis passagens no corpo Paulino. Sua dificuldade não é uma questão linguística, mas contextual. Enquanto o contexto atual e a falta de contextualização da passagem resultam em uma interpretação machista e sexista, este artigo demonstra que o autor, provavelmente Paulo, está subvertendo as expectativas de seu contexto no que se refere aos códigos domésticos. Através de estudos e uma análise contextual e co-textual, argumento que a passagem demonstra uma subversão de papéis de gêneros que era radical não somente no contexto inicial, como radicalmente relevante ao contexto atual.

Palavras-chave: Gênero, Paulo, Subversão, Contextualização, Efésios.

\section{A SUBVERSION OF GENDER ROLES IN EPHESIANS: A CO-TEXTUAL AND CONTEXTUAL ANALYSIS OF EPHESIANS 5:18-33}

\section{ABSTRACT}

The fifth chapter of Ephesians presents one of the hardest passages from the Pauline corpus. Its difficulty lies not in linguistics, but contextual matters. While the current context and the lack of contextualization of the passage contributes to a sexist and patriarchal interpretation, this article demonstrates that the author, who is probably Paul, subverts the expectations of his own context in what refers to household-codes. Through studies and an analysis of the context and co-text, I argue that the passage demonstrates a subversion of gender roles that is radical not only in its initial context, but also radically relevant to the current context.

Keywords: Gender, Paul, Subversion, Contextualization, Ephesians.

* Estudante de Filosofia e Estudos Bíblicos no Southeastern Baptist Theological Seminary, na Carolina do Norte, EUA. Mentor de Grego Koiné para estudantes de bacharelado, mestrado e doutorado.116natan@gmail.com 


\section{LA SUBVERSÍON DE LOS PAPELES DE GÉNERO EN EFESIOS: UNA ANÁLISE CO-TEXTUAL Y CONTEXTUAL DE EFESIOS 5:18-33}

\section{RESUMEN}

El capítulo cinco de Efesios presenta uno de los más difíciles pasos en el cuerpo Paulino. Su dificultad no es una cuestión lingüística, sino contextual. Mientras que el contexto actual y la falta de contextualización del paso resultan en una interpretación machista y sexista, este artículo demuestra que el autor, probablemente Pablo, está subvirtiendo las expectativas de su contexto en lo que se refiere a los códigos domésticos. A través de estudios y un análisis contextual y co-textual, argumento que el pasaje demuestra una subversión de papeles de géneros que era radical no sólo en el contexto inicial, como radicalmente relevante al contexto actual.

Palabras clave: Género, Pablo, Subversión, contextualización, Efesios

\section{INTRODUÇÃO}

O capítulo cinco da carta de Efésios contém um dos mais antigos códigos domésticos cristãos. A história da apropriação indevida desta passagem é longa, e Virginia Mollenkott elencou boa parte deste movimento que se esconde atrás da fidelidade à "Palavra de Deus" (Virginia Ramey MOLLENKOTT, 2003, p. 37-42). A interpretação deste texto, dentro do contexto greco-romano e judeu, revela um "novo" significado às antigas palavras do autor. Dentro do co-texto da carta e do contexto histórico, Efésios cinco lê que o amor auto-sacrificial do Cristo serve como a forma que modela a maneira como o marido lida com sua esposa, e como a esposa deve reciprocar com respeito e louvor se, e somente se, o marido lhe provê amor e o cuidado adequado.

\section{CONTEXTO AUTORAL}

Por mais que exista uma variante textual significante no primeiro verso no que se refere a audiência, a questão mais importante é se o autor da carta realmente é Пa?]入 oৎ (Paulo) ou não-a maioria dos acadêmicos diria que não. Nicholas Thomas Wright nota que, em certas universidades, acadêmicos juniores são incentivados a ignorarem Efésios completamente em estudos paulinos para preservarem sua imagem 
"acadêmica" (Nicholas Thomas WRIGHT, 2013, p. 59). Apesar da pressão social do meio acadêmico, David Meade demonstra que, enquanto é verdade que a maioria dos acadêmicos atuais não acredita que Paulo escreveu Efésios, isto não está tão claro quando investigamos a questão de forma histórica e tratamos apenas daqueles que engajaram algum tipo de argumentação (David G. MEADE, 1986, p.139). Sabemos que muitos querem afirmar que Paulo escreveu Efésios simplesmente para corroborar suas pressuposições quanto a qual tipo de texto "Deus", aparentemente, teria "escrito". No entanto, o consenso acadêmico quanto a tradição religiosa encontra o mesmo problema: tanto crenças teológicas quanto ad populum não podem decidir, a priori, o resultado da análise histórica e textual. Mas, mesmo com esta observação, podemos notar, junto a Garwood Anderson e Wright, que um argumento apologeticamente motivado não é, automaticamente, destituído de seu mérito como uma evidência plausível (Garwood ANDERSON, 2016, p. 185; Nicholas Thomas WRIGHT, 2013, p. 60; 1993, p. 10-11). Com a intenção de ser crítico a respeito da autoria desta carta, precisamos analisar a sua história de recepção, a estrutura do texto e seu conteúdo.

No que se trata da história da recepção de Efésios, as anotações de Desiderius Erasmus são as mais antigas referências relacionadas às dúvidas quanto ao estilo da carta (Desiderius ERASMUS, 2017, p. 110). No entanto, os mais antigos proponentes da não-autoria Paulina da passagem são do século dezoito e dezenove (Edward EVANSON, 1792; Leonhard USTERI, 1824, p.3-8; Wilhelm Martin Leberecht de WETTE, 1826, p. 254-265; Ferdinand Christian BAUR, 1845, p. 449-455; cf. Andrew T. LINCOLN, 1990, p. lix). Visto que tal ceticismo parece ter se consolidado mais tarde, alguns, como Clinton Arnold, afirmam que a igreja antiga era unanimemente a favor da autoria paulina desta carta (Clinton ARNOLD, 2010, p. 57). Ernest Best, no entanto, em seu comentário crítico, demonstra que somente Policarpo e Ignácio certamente conheciam a carta e afirmavam sua autoria Paulina (Ernest BEST, 1998, p.17). Não obstante, as duas citações de Paulo encontradas na Exegese da Alma 2.6.131 e na Hipóstase dos Arcontes 2.86.20-25 revelam muito sobre a recepção da autoria da carta, dado sua distância geográfica e temporal de Éfeso e da carta (Elaine PAGELS, 1996, p. 472). Harold Hoeh- 
ner assegura seus leitores de que a autoria Paulina é a visão com mais suporte tradicional ao decorrer da história (Harold W. HOEHNER, 2002, p. 20; Garwood ANDERSON, 2016, p.185). Entretanto, o argumentum ad antiquitatem não pode ser gratuitamente aceito, dado que sabemos de muitas instâncias nas quais os Pais da Igreja apresentaram testemunhos que não são confiáveis (Mark HARDING, 2004, p. 164-166; Ernest Cushing RICHARDSON, 1892, p. 353; Frederik Fyvie BRUCE, 1990, p. xxxvi-xxxvii; James H. CHARLESWORTH, 1992, p. 541).

Estruturalmente, o estilo de Efésios difere de maneira radical das cartas que não são disputadas no cânon cristão (Bart D. EHRMAN, 2013, p. 184-185; Andrew T. LINCOLN, 1990, p. xxxvii-xlvii; Ernest BEST, 1998, p. 27-32). Este assunto, entretanto, não é claro, visto que estilo é um termo difícil de definir e a falta de estudos sociolinguísticos no Novo Testamento torna este argumento com pretensões científicas em algo extremamente subjetivo (Matthew Brook O'DONNELL, 2005, p. 228; Andrew W. PITTS, 2013, p. 115; Ernest BEST, 1998, p. 31; Nicholas Thomas WRIGHT, 2013, p. 60). As análises estilo-estatísticas feitas por Kenneth J. Neumann tem consistentemente apontado que Efésios tem mais material em comum com cartas Paulinas do que com cartas decididamente não-Paulinas, o que é esperado caso a carta seja, decididamente, uma fabricação falsa (Kenneth J. NEUMANN, 1990, p. 218-225). A avaliação do perfil das cartas baseada em registros demonstra que a porcentagem de variação entre Efésios e outros perfis Paulinos é completamente aceitável—não existem divergências maiores que 98\%, que é uma margem de variação aceitável na sociolinguística (Andrew PITTS, 2013, p. 123 e 132). Logo, estilo como algo isolado, não pode responder à questão de quem escreveu Efésios-talvez esta abordagem nem sequer seja útil por conta de seu caráter subjetivo (Kenneth NEUMANN, 1990, p. 217218). Isso não é, em si, um argumento positivo para a autoria Paulina. O que Kenneth Neumann conclui é, apenas, que uma conclusão sobre a autoria precisa ser feita baseada em outras questões além do estilo. Portanto, o pensamento do autor quanto a si mesmo, sua eclesiologia, soteriologia e escatologia, precisam ser analisadas em conjunto.

Ernest Best apresenta vários motivos para acreditar que a carta foi escrita por um homem, o que é esperado (Ernest BEST, 1998, p. 7-8). O 
autor da carta lida com a luta cristã em termos masculinos (Efésios 6:13),

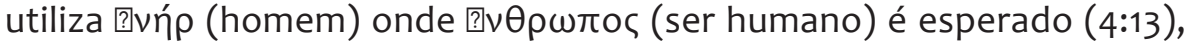
descreve o casamento como uma ação do homem (5:31), usa $\pi$ ópvos (prostituto) onde 1 Coríntios 6:15 usa $\pi$ ópvn (prostituta, 5:5), escreve que ladrões homens devem parar de roubar (4:28) e pais homens recebem instruções para seus filhos (6:4). Além disso, no contexto do século da Era Comum, é difícil de imaginar que uma mulher tenha tido a oportunidade devida de escrever. O autor da carta, certamente um homem, acredita que Paulo, junto com outros gentios que eram perdidos, estavam desorientados em suas paixões da carne. O autor crê que ele mesmo já foi um filho da ira (2:3), o que é diametricamente oposto ao que Paulo escreve sobre si mesmo em Filipenses 3:4-6. Entretanto, Bart Ehrman aponta que o auto-entendimento autoral não é uma questão fácil de resolver (Bart EHRMAN, 2013, p. 186). Harold Hoehner ignora esta questão extremamente relevante completamente, sem explicar seus motivos (Harold HOEHNER, 2002, p. 316-324). Estudantes que estão interessados no auto-entendimento autoral ganharão mais investigando James D. G. Dunn e outros (James D. G. DUNN, 1999, p. 174-193; 2009, p. 522-541; Matthew SKINNER, 2018, p. 171; Sigurd GRIDHEIM, 2011). A melhor maneira de explicar esta divergência textual é que o autor utiliza a primeira pessoa do plural como uma referência literária, ao invés de uma referência material. Além disso, Frederik Fyvie Bruce clarifica que Efésios 2:3 não parece ser uma referência ao nós como Paulo e Judeus, mas meramente como Paulo e Gentios, dado que Judeus são mencionados somente em 2:11 (Frederik Fyvie BRUCE, 1984, p. 283-284).

A eclesiologia elaborada de Efésios é mais um sinal de como as cartas de Paulo tem sido estudadas de forma pobre do que evidência

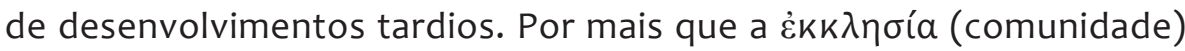
seja apenas usada como um símbolo da congregação local em cartas Paulinas, a preocupação pela unidade do corpo e a natureza circulatória da carta poderia explicar o desejo de Paulo de falar da natureza universal

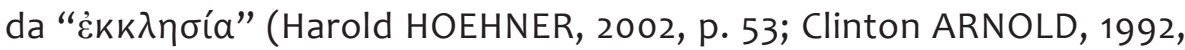
p. 164-165; 1993, p. 241; Douglas CAMPBELL, 2014, p. 329).

Uma das surpresas teológicas nesta carta é que ela não foca na cruz, mas sim na ressurreição, exaltação, e liderança cósmica do Cristo 
(Andrew T. LINCOLN, 1990, p. Ixiii; 1992, p. 167; 1993, p. 247;). A definição de Nicholas Thomas Wright de uma contradição nos é útil: duas ou mais passagens fazendo afirmações irreconciliáveis sobre o mesmo tópico, no mesmo contexto (Nicholas Thomas WRIGHT, 1993, p. 5-6). Dada esta definição, a mudança de foco não é, propriamente falando, uma contradição, mas sim um sinal da situação da carta e do seu autor, que está explorando ideias diferentes, mudando seu pensamento, e desenvolvendo sua teologia. James D. G. Dunn argumenta que a kerygma de Paulo apenas argumenta contra, sem rejeitar completamente, seus mestres (James D. G. DUNN, 2006, p. 24-25). Finalmente, sabemos que os primeiros anos do Cristianismo eram tão diversos quanto os dias atuais (Rudolf BULTMANN, 1970, p. 138-142; Larry HURTADO, 2016, p. 10-12; Garwood ANDERSON, 2016, p. 184). Por conta disso, não há problema algum em aceitar que Paulo era capaz de mudar suas ideias, focando em áreas diferentes e argumentando somente baseando-se no que era necessário para sua audiência.

Em Efésios, o retorno eminente do Cristo é completamente abandonado, por mais que exista uma ênfase na consumação de todas as coisas (Andrew T. LINCOLN, 1990, p. Ixiv; David MEADE, 1986, p. 140). Antes de afirmar que o autor não demonstra sensibilidade escatológica, é preciso considerar que Michael Gorman aponta a era que há de vir (1:21) e o dia da redenção (4:30) como elementos escatológicos (Michael GORMAN, 2017, p. 581). De forma similar, Nicholas Thomas Wright, em sua biografia de Paulo, destaca nos três primeiros capítulos vários elementos do presente-que-há-de-vir, o que parece assegurar um balanço de elementos escatológicos implícitos e explícitos (Nicholas Thomas WRIGHT, 2018, p. 299). Tais elementos parecem tomar o lugar do retorno eminente, e também parecem ter sobrevivido a atualização do pensamento escatológico do autor, se este for Paulo. O que parece válido, em vista do abandono completo do retorno do Cristo nesta carta, é que Paulo vivenciou uma mudança e amadurecimento radical de seu pensamento e, como alguns cristãos contemporâneos, passou a acreditar que o fim do mundo não é algo tão próximo como inicialmente parecia. A conclusão do assunto é que Paulo poderia muito bem ter escrito esta carta, que a igreja antiga cria que ele de fato escreveu a carta, e que 
nenhuma preocupação, seja ela teológica ou estilística, pode assegurar a rejeição do argumento tradicional (Matthew SKINNER, 2018, p. 177).

Mesmo que este breve argumento seja rejeitado, o caráter autoritário da carta é, para boa parte dos cristãos, derivado de seu status canônico, não de seu autor. Mesmo como uma epístola falsificada, ela ainda pode ser lida como sendo paulina de forma construída, como sugere Brevard Childs e Garwood Anderson (Garwood ANDERSON, 2016, p. 220-224; Brevard CHILDS, 2008)'. Outra opção seria entender a carta como o caso mais antigo de uma interpretação Paulina, seja esta feita por um indivíduo ou uma comunidade (Garwood ANDERSON, 2016, p. 223). Dada estas opções positivas, uma harmonização forçada entre Efésios e outras cartas é completamente desnecessária (Matthew SKINNER, 2018, p. 169-170). Entretanto, enquanto um status pseudônimo não seria nada perturbador, podemos concluir que as evidências supramencionadas apontam Paulo como o autor da carta e, portanto, este artigo irá se referir ao autor da carta como Paulo.

\section{ANÁLISE LÉXICA E ESTRUTURAL}

Antes de analisar o contexto histórico da carta, analisaremos notas léxicas e estruturais que possam nos ajudar a entender a carta em seus próprios termos. Tanto $\pi \lambda \eta \rho \circ$ ? $\sigma \theta \varepsilon$ (sejam enchidos) quanto $\mu$ ? $\mu \varepsilon \theta u ́ \sigma k \varepsilon \sigma \theta \varepsilon$ (não sejam embriagados), no versículo 18 do capítulo 5 , são usados na voz passiva, sugerindo consentimento. Enquanto ambos termos são preceitos, o resultado da ação não é algo praticado pelo agente, ou seja, enquanto os leitores são chamados a serem cheios, o "enchimento" em si não é algo que o sujeito faz (Andreas KÖSTENBERGER, Benjamin MERKLE, e Robert PLUMMER, 2016, p. 199). Os objetos de ambos termos são dativos de modo. Logo, existe um contraste entre o enchimento por meio do espírito e a embriaguez por meio do vinho (Archibald Thomas ROBERTSON, 2006, p. 532-535; William ARNDT, Frederick W. DANKER, Walter BAUER, e F. Wilbur GINGRICH, 2000, p. 625; William J. LARKIN, 2009, p. 124; Gerhard KITTEL, Geoffrey W. BROMILEY, e Gerhard FRIEDRICH, 1964, p. 291). A voz passiva, neste termo, sugere a ideia de consentimento para o espírito ou o vinho. Neste texto, todos

Para uma resposta à proposta de Brevard Childs, veja: KLOHA, Jeffrey, 2009, p. 156-169. 
os leitores, sem distinção, são chamados a aceitar uma "submissão" e rejeitar a outra.

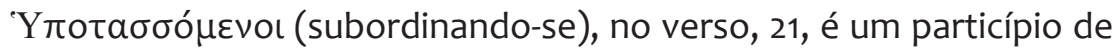
resultado que não carrega nenhuma força imperativa no verso seguinte. Tal dado é relevante pois tal particípio passivo indica o reconhecimento de uma certa estrutura da entidade a qual o sujeito se submete (Daniel B. WALLACE, 1996, p. 651; cf. William LARKIN, 2009, p130). Portanto, traduções que utilizam este particípio como um imperativo perdem a força da submissão não somente como um ato que enche o crente do Espírito, mas também como algo requerido de ambos homens e mulheres (David Alan BLACK, 1998, p. 37; Walter BAUER et al., 2000, p. 1041; contra William LARKIN, 2009, p. 129).

O Espírito, como sujeito (Ernest BEST, 1998, p. 508-509), sugere a ideia principal de submissão, não obediência (Gerhard KITTEL, Geoffrey BROMILEY e Gerhard FRIEDRICH, 1964, p. 424). O verso 22 é logicamente, e não gramaticalmente, dependente no verso 21 (Steven E. RUNGE,

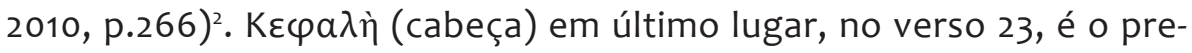
dicado nominativo de $\dot{\varepsilon} \sigma \tau \iota$ (ele é), que sugere um sentido de domínio tal como a posição autoritária de Cristo em 1:22 (William LARKIN, 2009, p. 131-132). "Cabeça" é o termo que denota o mais alto modo de "ser" em uma estrutura, e isso parece indicar a maneira como a esposa se relaciona com o marido. Veja que Cristo é o cabeça da comunidade ( $4: 15 ; 5: 23)$, e este lidera o universo (1:22). Paulo, porém, nunca faz a conexão entre ser o "cabeça" e ser o "líder" no tratamento entre marido e mulher em Efésios (Walter BAUER et al., 2000, p. 542; Eugene Albert NIDA e Johannes P. LOUW, 1996, p. 738; James Hope MOULTON e George MILLIGAN, 1930, p. 342; Horst Robert BALZ e Gerhard SCHNEIDER, 1990, p. 285). Além disso a evidência contextual e co-textual, que é explorada logo abaixo, sugere um co-sentido de "fonte" (Cynthia Long WESTFALL, 2013, p.568).

Os imperativos são direcionados a toda a audiência da carta. Paulo apresenta quatro maneiras de sua audiência ser cheia do Espírito. Os mandamentos específicos para esposas e maridos são apenas modos

Sobre a interação da ausência do verbo com a sessão anterior, veja: MERKLE, Benjamin, 2017, p. 190-191. 
particulares de experimentar o enchimento do Espírito. O particípio do verso 21 ilumina quem deve se submeter - todos se submetem a todos.

\section{ANÁLISE CONTEXTUAL}

Textualmente, tendo sido ressurretos com Cristo, seguidores

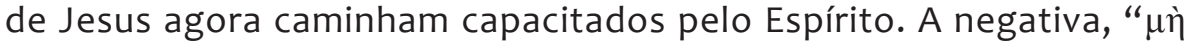
$\mu \varepsilon \theta u ́ \sigma \kappa \varepsilon \sigma \theta \varepsilon$ ớv@" (não sejam embriagados com vinho), e a positiva, " $\pi \lambda \eta \rho 0 \tilde{\sigma} \sigma \theta \varepsilon \dot{\varepsilon} v \pi v \varepsilon v ́ \mu \alpha \tau \imath$ " (sejam cheios no espírito), guiam a sessão em questão. Os verbos seguintes indicam maneiras nas quais tal "enchimento" é possível. A passagem que segue a sessão do capítulo 5 , que trata de batalha espiritual, pode sinalizar que tudo que precede é entendido como parte da vida espiritual, ou pelo menos do processo de santificação (Nicholas Thomas WRIGHT, 2018, p. 298-299). Enquanto a significância da parte que precede esta passagem é que ser cheio do Espirito implica ordem doméstica, a importância da parte que sucede indica que isso não é apenas uma questão de ordem social - é uma questão espiritual (Clinton ARNOLD, 2010, p. 370; Timothy G. GOMBIS, 2005, p. 317-330). Este "agrupamento" não somente coloca em foco os relacionamentos do lar, quanto também coloca em cheque qualquer acusação de que o foco nas relações sociais seja algo separado da questão "espiritual". Tal platonismo que separa a matéria "verdadeira" do espírito das sombras sociais não se assemelha ao que Paulo parece estar fazendo nesta passagem.

A carta é situada em um período no qual códigos domésticos eram comuns na literatura judaica, greco-romana e cristã (John FITZGERALD, 1992, p. 80-81). Paulo, então, não era o primeiro ou último a tentar elaborar uma maneira de organizar o lar de acordo com princípios teológicos. Além disso, a carta alude a, e cita, textos judeus, indicando que a continuidade no argumento Paulino entre a primeira e segunda era. Ou seja, tal ordem não é apenas um produto do contexto social de Paulo, mas também, de sua tradição socio-religiosa judaica. Por mais que a história da criação não tenha sido, aparentemente, escrita para demonstrar como Deus quer que humanos se casem, Genesis 2:24 é citado. A significância disso é que, para Paulo, o tema de união é ligado ao contexto literário judaico (Frank THIELMAN, 2007, p. 825-828). 


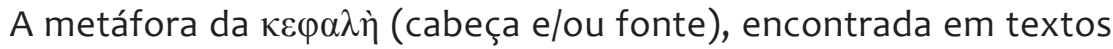
greco-romanos, indica que o corpo deve trabalhar pelo seu bem comum através de serviços prestados à cabeça, que é a fonte dos benefícios do corpo e a autoridade sobre o corpo (Fílon, De Abrahamo 150; De Vita Mosis 2.30; Specialibuts Legibus 184; Dião Cristóstomo, Tarsica

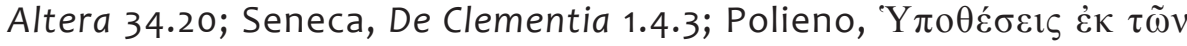

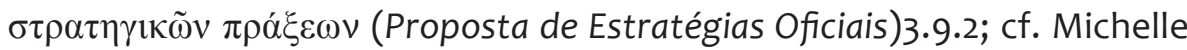
LEE-BARNEWALL, 2013). Nestas passagens e outras que são citadas por Michelle Lee-Barnewall, o/a leitor/a pode perceber que, enquanto o contexto judaico é basicamente colado sobre esta passagem, existem diferenças significativas entre as metáforas no mundo greco-romano e no texto de Paulo.

No contexto greco-romano, a sociedade era organizada por hierarquias (superior/inferior), status social (mais/menos), e função sexual (penetrador/penetrado; Aristóteles, De Moto Animalium 728.1820, 737.25-35, 775; cf. Cynthia WESTFALL, 2013, p. 568). Já no contexto judaico, Êxodo 21:10 era utilizado para descrever diretrizes à homens e mulheres no casamento. Nutrir, vestir, e alimentar eram os papéis que foram consolidados como regras para as mulheres na relação familiar, dando origem a um tipo de estereótipo baseado na Escritura (Shalom M. PAUL, 1969, p. 48-53; Mishná Ketubot 5.5, 5.8; Cynthia WESTFALL, 2013, p. 571). Aqui, porém, o/a leitor/a pode, também, começar a perceber que existe, de forma não surpreendente, uma atualização deste estereótipo no que Paulo escreve.

\section{ANÁLISE INTEGRAL}

Na primeira frase, Paulo contrapõe que a audiência não deve ser intoxicada pelo vinho, porque $\dot{\varepsilon} v \tilde{\omega} \dot{\varepsilon} \sigma \tau \imath v \dot{\alpha} \sigma \omega \tau i ́ \alpha$ - nele se encontra aquilo que é oposto a salvação. A audiência deve, de forma alternativa, permitir-se ser enchida pelo Espírito através de ações concretas.

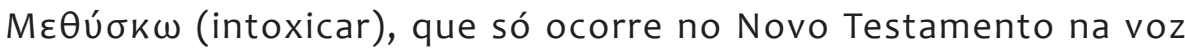
passiva, serve então como um contraste entre dois tipos de ações que demandam permissão (Walter BAUER et al., 2000, p. 627). Ao negar a embriaguez, a audiência será abastecida com o Espírito através do falar com o outro através de Salmos, hinos, e cânticos espirituais - todos 
vindo do coração, direcionados ao Senhor. O mesmo acontece quando a comunidade se alegra em todo tempo no nome de seu senhor Jesus Cristo, e seu Deus, o Pai. Em último lugar, todos, não somente mulheres, nesta comunidade são enchidos com o Espírito enquanto estes se submetem ao próximo. O particípio de modo não é um título gramatical deste Haustafel (código doméstico), e deve ser lido apenas como um dispositivo literário. Neste caso, a divisão dos parágrafos da Tyndale House Greek New Testament é muito mais precisa do que a da United Bible Societies (Benjamin MERKLE, 2017, p. 183-191). Isso é importante porque leitores/as de bíblias em português não sabem que não existe imperativo algum no verso 22, e também não sabem que o verso 22 não inicia um novo tópico, como a Almeida Revista e Atualizada estrutura sua página. Existe uma conexão literária em todo o capítulo, mas especificamente do verso 18 em diante, que não justifica a separação do verso 22 em uma nova sessão.

Enquanto homens são abordados de forma direta com dois verbos finitos e ỏ $\varphi \varepsilon i ́ \lambda \omega$ (ser devedor), um verbo forte de obrigação, mulheres nunca, em toda esta passagem, recebem imperativo algum do autor. $O$ peso do particípio do verso 21 tem sua força no verso 21, não no 22 . Ou seja, no verso 21 todos são chamados a se submeterem uns aos outros como algo feito ao Senhor (Cynthia WESTFALL, 2013, p. 577-578). O verso 22 continua este tema demonstrando como as esposas podem fazer isso de forma específica, e logo adiante como o marido pode fazer isso de forma específica. Não é razoável ler esta sessão como se a única maneira de se submeter um ao outro seja fazendo aquilo que Paulo sugere aqui. Suas considerações são guias genéricos para a boa relação, não uma nova Torah que seguidores de Paulo devem obedecer ao pé da letra.

Nesta passagem, as esposas fazem apenas aquilo, e nada além daquilo, que todos os outros membros do corpo fazem: elas se submetem ao próximo, dada sua reverência ao Senhor. Sua função está longe de ser particular. Ademais, elas submetem-se aos seus maridos $\hat{\omega} \varsigma \tau \tilde{\varphi}$ кupí (como ao mestre), o que acaba por limitar a extensão de sua submissão como algo auto voluntário e feito de livre escolha (Virginia MOLLENKOTT, 2003, p. 46). "Como ao Senhor" quer dizer exatamente isso. Da mesma forma que a submissão ao Senhor é feita de maneira 
livre, espontânea, e em resposta a uma ação de amor que precede sua reciprocidade, assim ela deve se relacionar com seu marido. De forma alguma é legítima a leitura que entende a relação entre esposas e o Senhor de outra maneira. Por fim, ? $v$ $\pi$ a $v \tau i ́$ (em tudo) refere-se à função salvífica do verso 23 e aos atos de auto entrega de Cristo do verso 25. Isso quer dizer que a esposa se submete (no presente, não um imperativo) ao marido da mesma maneira que a igreja se submete ao seu salvador. Para tornar isso mais explícito: a igreja se submete a um salvador que, antes da resposta da igreja, decidiu sacrificar tudo por esta igreja--enquanto a ação da igreja é baseada na ação anterior do Cristo, a ação do Cristo, que é o iniciador do processo, não necessita de nenhum ato anterior por parte da igreja. Deste modo, então, Paulo quer que o relacionamento no lar funcione.

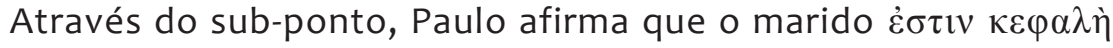

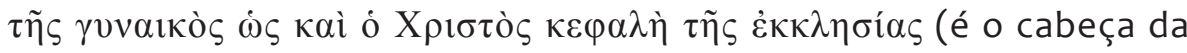
esposa assim como o Cristo é o cabeça da comunidade). Aqui, Paulo concorda com a norma social padrão, na qual o marido é a fonte dos recursos e autoridade da esposa. Entretanto, da mesma forma que Paulo introduz a metáfora, ele abandona seu relacionamento com os papéis de gênero (Michelle LEE-BARNEWALL, 2013, p. 605). Argumentando o contrário do contexto social, no qual o corpo trabalha para a cabeça, Paulo reverte os papéis de gênero, escrevendo que a entidade superior, maior, e penetradora deve trabalhar para a entidade inferior, menor e penetrada (Michelle LEE-BARNEWALL, 2013, p. 599, p. 612). Enquanto muitas leitoras sentem-se oprimidas com as palavras de Paulo--e com razão, visto que muitos intérpretes em meios eclesiásticos parecem estar mais interessados no estabelecimento de poder do que com a vida das mulheres nas congregações locais - neste caso, e este não é, necessariamente, o caso com todas as passagens familiares do Novo Testamento, a passagem acaba por pesar no lado dos homens, e não no das mulheres. Com o título de salvador, que acaba por confundir muitos leitores, a esposa submete-se ao marido somente como ela se submete ao Senhor: de maneira livre; somente quando ele é, de fato, a salvação de seu corpo, através de atos providenciais e preservativos. O homem, então, pode sim carregar o título de cabeça ou até de salvador, mas 
este terá de arcar com as implicações dos termos no contexto cristão. A natureza recíproca e condicional, comum na literatura greco-romana, é utilizada por Paulo de forma memorável para balancear as diretrizes e colocar a carga no marido através de suas palavras às mulheres (Cynthia WESTFALL, 2013, p. 595).

De forma inesperada, mulheres não são nem sequer chamadas a amarem seus maridos. Tal pedido seria sábio em uma época na qual as palavras de mulheres não tinham tanto valor no que se refere a quem elas seriam obrigadas a casar. A subversão desta expectativa ocorre em conjunto à subversão do sexismo patriarcal, no qual maridos são chamados a demonstrar afeto, algo que é extremamente raro na literatura sincrônica (Virginia MOLLENKOTT, 2003, p. 46-47; Clinton ARNOLD, 2010,

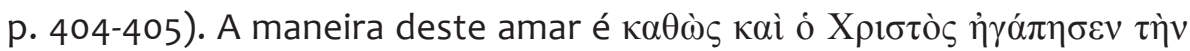

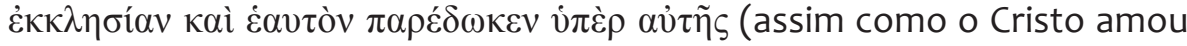
a comunidade e entregou-se a si mesmo para esta). Ou seja, maridos devem amar suas esposas exatamente da mesma maneira na qual o Cristo amou a igreja e a si mesmo se entregou por ela. O peso retórico é que, enquanto nos versos anteriores Paulo expressa a responsabilidade do homem através de palavras à suas esposas, agora o foco está completamente nos homens e Paulo se dirige diretamente a eles. Agora fica ainda mais claro como a analogia do "salvador" é limitada pelo amor do Cristo pela Igreja e por sua vida de sacrifícios a ela (Virginia MOLLENKOTT, 2003, p. 42, p. 46, p. 48; Cynthia WESTFALL, 2013, p. 589-590). Muitos/as leitores/as querem, por algum motivo, elaborar o relacionamento entre Cristo e a igreja como de Senhor e escravo. Enquanto tal analogia parece tomar conta das diversas passagens em

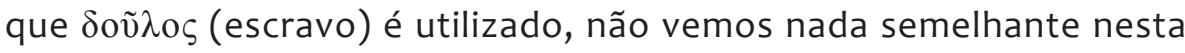
carta (James D. G. DUNN, 2009, p. 1119). De fato, todas as referências a escravos estão presentes no capítulo 6 , e em todas as quatro vezes em que o termo está presente ele é usado literalmente, descrevendo o relacionamento dos escravos aos seus senhores e ao Senhor. O relacionamento entre o marido e a esposa não é, nem de longe, parecido com a relação de autoridade entre um escravo e seu senhor.

O marido ama através do lavar, nutrir, e apreciar - funções que estão diretamente relacionadas às três necessidades citadas anteriormente 
(Êxodo 21:10; cf. Mishná Ketubot 5.5, 5.8). De forma clara, Paulo demanda que homens amem suas mulheres em seus termos: Paulo literalmente ordena que homens tomem sobre si o papel feminino do lar como uma demonstração de afeto (Cynthia WESTFALL, 2013, p. 572, p. 588, p. 590594). Logo, agindo como mulheres, homens agora são capazes de amar suas esposas da mesma forma como Cristo amou sua Igreja. Os papéis de gênero são, novamente, revertidos, tudo para que a submissão mútua seja uma realidade nesta comunidade. Portanto o marido, e não a mulher,

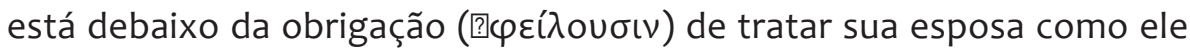
lida consigo mesmo; ele deve designar a ela seu status de maior, superior e penetrador. Ele não somente deve tomar sobre si o jugo que pesa sobre ela, mas também deve elevá-la ao nível que este acredita estar (no contexto da carta, o nível seria muito mais alto do que da mulher). Éticas sociais e domésticas são colocadas lado a lado, o que demonstra quão confortável esta passagem está no contexto do microcosmo para o macrocosmo da Política de Aristóteles. Paulo, porém, subverte as expectativas sociais deste contexto através da maneira como ele interage com seu contexto, evidente no co-texto. Para Paulo, o lar não é o microcosmo que serve como base do macrocosmo da cidade. Pelo contrário, o macrocosmo de Cristo e da igreja é o modelo do microcosmo do lar.

Paulo diz que ninguém nunca odiou seu próprio corpo, o que poderia ser verdade para a maioria dos membros das classes superiores da $\pi$ ó $\lambda$ เ (cidade). A ideia de Gênesis 2:24 é que homens e mulheres agora são o mesmo corpo, e tem o mesmo status ontológico. Como um homem, ele deve cultivar e nutrir sua esposa-algo que era esperado da esposa, e não do marido. As distinções entre papéis de gênero são quebradas para que a unidade total possa ser adquirida. Ambos são um em seu relacionamento, e também um em Cristo, o que novamente traz o leitor de volta ao tema de submissão-mútua e ao "um-ao-outro" dos particípios que seguem o verso 18 (Michelle LEE-BARNEWALL, 2003, p. 613).

A força da analogia de Paulo é demonstrada não no contexto relacional, no qual o marido e a esposa agem de forma concordante com o contexto judeu ou greco-romano, mas no contexto eclesiástico, como parte do "mistério" da Igreja. Paulo termina a primeira seção do código requerendo que todos e cada marido ouçam bem esta carta, para que 
possam amar suas próprias esposas. Eles fazem isso "para que" suas esposas possam respeitá-los, o que revela a natureza condicional do texto,

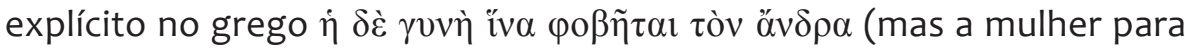
que respeite o marido). Ao contrário da maioria, se não todas, as traduções, îv $\varphi$ o $\beta \tilde{\eta} \tau \alpha l$ (para que tema) não forma um paralelo com $\alpha \gamma \alpha \tau \alpha ́ \tau \omega$ (amem). Ou seja, existe, no texto, uma ideia condicional, e dizer que a mulher deve se submeter ao homem independente da maneira como o marido trata a mulher é ir além e ao contrário àquilo que o texto grego indica. O uso imperativo do subjuntivo é extremamente raro, ou talvez até inexistente (Margareth G. SIM, 2011, p. 75-98). Por conta disso, o contexto literário deve determinar seu uso. A cláusula dependente, que é mais comum, se encaixa no contexto de forma mais confortável, visto nenhum mandamento é dado a mulheres nesta passagem (Cynthia WESTFALL, 2013, p. 574). Qualquer maneira de explicar ou traduzir esta passagem sem a natureza condicional perpetua não somente um mal uso da língua, como também força esposas devotas à leitura da Bíblia a fazerem algo que nunca lhes foi sugerido.

Cristo adquiriu seu status de respeito sobre a Igreja através de atos sacrificiais e amorosos. O marido deve trabalhar conforme as diretrizes apresentadas, o que permite que sua esposa cumpra seu chamado, que é o de respeito. Novamente, para que um possa agir, o outro tem de agir, o que revela a natureza do "um-ao-outro", evidente no uso reflexivo do pronome $\dot{\varepsilon} \alpha v \tau o \tilde{v}$ (a si mesmo) nesta passagem. Paulo está, de certa forma, lembrando o marido de que, por mais que ele seja acostumado a receber seu respeito de acordo com normas daquela sociedade, como seguidor de Jesus, é através da reciprocidade que ele será respeitado, não pelo seu trabalho fora do lar ou seu "status" perante o público (Cynthia WESTFALL, 2013, p. 595). Ele é a fonte do cumprimento do chamado da esposa; aquele que torna possível sua esposa respeitá-lo livremente, como um ato gracioso de retorno de favores (Cynthia WESTFALL, 2013, p. 562-572, p. 580-595).

\section{CONCLUSÃO E REFLEXÃO}

Quando lida em isolamento, com o contexto do século 21, Efésios 5:18-33 serve como uma maneira de perpetuar o machismo e outras 
ideologias que possibilitam abusos de autoridade dentro do lar. No entanto, o contexto do primeiro século abre novas possibilidades de interpretação, permitindo que esta passagem seja lida justamente como uma ideologia oposta a este problema. No contexto judaico, vemos que mulheres tinham funções específicas no lar, mas Paulo subverte isso requerendo que homens, que ganhavam seu respeito através de seu trabalho público, agora trabalhem como mulheres dentro do lar, em isolamento, ganhando então o respeito verdadeiro de sua outra metade. No contexto greco-romano, a cabeça era a fonte e autoridade do corpo, o que era entendido como algo que implica que o corpo deve trabalhar para a preservação da cabeça. Paulo subverte esta ideia afirmando a expressão, mas tornando a cabeça como algo que deve trabalhar para o corpo, e não o contrário. Paulo demanda um tipo de união que só é possível através da reciprocidade, e requer que o homem, como o "cabeça" (de forma levemente irônica), inicie essa união através do tomar da natureza do "outro", algo bem presente no exemplo de Cristo, como Paulo também diz em Filipenses 2:5-11.

Esta passagem tem seu caráter subversivo preservado no contexto atual. Para o cristão contemporâneo, Paulo ainda sabota os papéis de gênero através do amor de Cristo e de seu relacionamento auto-sacrificial com sua Igreja. Se homens ainda desejam o status de "cabeça", eles podem tê-lo, porém, isso significa que eles devem agir com uma maior ênfase sacrificial em suas relações com ela. É exegeticamente absurdo afirmar, tal como faz John Frame, que a mulher deve obedecer seu marido e que o marido não deve se submeter a sua esposa (John FRAME, 2008, p. 587, p. 633, p. 981-982). Mulheres são empoderadas pelos seus maridos, mas isso significa apenas que ele é a "porta" que permite que ela seja enchida pelo Espírito através de seus atos de louvor, respeito, e resposta submissa.

Por mais que as outras ações não recebam tanta ênfase no texto, todas são maneiras de experimentar o que Paulo chama de "enchimento". Homens e mulheres, maridos e esposas, devem submeter-se uns aos outros, em respeito e reverência ao Senhor. É interessante que alguns acadêmicos conservadores nem sequer citam 5:21 quando lidam com esta passagem (Daniel AKIN e Scott PACE, 2017; Norman GEISLER, 2003; 
Alan MYATT e Franklin FERREIRA, 2007; John MACARTHUR e Richard MAYHUE, 2017; et al.). Para que mulheres recebam sua honra e zelo, este verso não pode ser ignorado.

Esta passagem descreve o papel do homem de forma mais enfática, e de fato, o foco da passagem é nos homens. Porém, se este texto é um texto inspirado, então a liberdade do Espírito deve mover seus intérpretes a questionarem maneiras nas quais Paulo ainda fala no contexto atual. Cada congregação e contexto deve, de forma individual, decidir qual é a melhor abordagem para ela com este texto. Tudo que foi demonstrado é que o texto é sexista e machista somente no vácuo que carece de contexto antigo. Talvez tal abordagem seja um problema técnico, e se for, este texto e suas citações devem servir como um corretivo muito necessário. Se, porém, ela for de caráter ideológico, então pelo menos outros/as intérpretes agora tem a opção de ver por detrás da ideologia que se mascara como uma simples leitura da Palavra de Deus.

\section{REFERÊNCIAS}

AKIN, Daniel; PACE, Scott. Pastoral Theology: Theological Foundations for Who a Pastor is and What he Does. Nashville: B\&H, 2017.

ANDERSON, Garwood. Paul's New Perspective: Charting a Soteriological Journey. Downers Grove: IVP, 2016.

ARNDT, William; DANKER Frederick; BAUER, Walter; GINGRICH, F. Wilbur (Eds.). A Greek-English Lexicon of the New Testament and Other Early Christian Literature. $3^{\mathrm{a}}$ edição. Chicago: University of Chicago Press, 2000.

ARNOLD, Clinton. Ephesians: Zondervan Exegetical Commentary on the New Testament. Grand Rapids: Zondervan, 2010.

. Ephesians, Letter to The. In: HAWTHORNE, Gerald F.; MARTIN,

Ralph P.; REID, Daniel G. (Eds.). Dictionary of Paul and His Letters. Downers Grove: InterVarsity Press, 1993.

. Power and Magic: The Concept of Power in Ephesians in Light of its Historical Setting. Grand Rapids: Baker, 1992.

BALZ, Horst Robert; SCHNEIDER, Gerhard. Exegetical Dictionary of the New Testament - Vol. 2. Grand Rapids: Eerdmans, 1990.

BAUR, Ferdinand Christian. Paulus der Apostel Jesu Christi. Stuttgart: Becker \& Müller, 1845 .

BEST, Ernest. A Critical and Exegetical Commentary on Ephesians: International Critical Commentary. Edinburgh: T\&T Clark International, 1998. 
BLACK, David Alan. It's Still Greek to Me: An Easy-to-Understand Guide to Intermediate Greek. Grand Rapids: Baker Books, 1998.

BRUCE, Frederik Fyvie. Hebrews: New International Commentary on the New Testament. Grand Rapids: Eerdmans, 1990.

. The Epistles to the Colossians, to Philemon, and to the Ephesians: New International Commentary on the New Testament. Grand Rapids: Eerdmans, 1984.

BULTMANN, Rudolf. Theology of the New Testament. Waco: Baylor, 2007.

CAMPBELL, Douglas. Framing Paul: An Epistolary Biography. Grand Rapids: Eerdmans, 2014.

CHARLESWORTH, James H. Pseudonymity and Pseudepigraphy. In: FREEDMAN, David Noel (Ed.). The Anchor Yale Bible Dictionary - Vol. 5. New York: Doubleday, 1992, p. 540-541.

CHILDS, Brevard. The Church's Guide for Reading Paul: The Canonical Shaping of the Pauline Corpus. Grand Rapids: Eerdmans, 2008.

DE WETTE, Wilhelm Martin Leberecht. Lehrbuch des Neuen Testaments. Berlin: Reimer, 1826.

DUNN, James D. G. Beginning From Jerusalem. Grand Rapids: Eerdmans, 2009. . The Theology of Paul the Apostle. Grand Rapids: Eerdmans, 2006. . 'Who Did Paul Think He Was? A Study of Jewish Christian Identity'.

New Testament Studies, v. 45, 1999, p. 174-193.

EHRMAN, Bart D. Forgery and Counterforgery: The Use of Literary Deceit in Early Christian Polemics. New York: Oxford, 2013.

ERASMUS, Desiderius. Annotations on Galatians and Ephesians: New Testament Scholarship - Vol. 58. Toronto: University of Toronto Press, 2017.

EVANSON, Edward. The Dissonance of the Four Generally Received Evangelists and the Evidence of Their Respective Authenticity Examined. England: Ipswich, 1792.

FRAME, John. A Theology of Lordship: The Doctrine of Christian Life. Phillipsburg: $P \& R, 2008$.

GEISLER, Norman. Systematic Theology: God, Creation. Minneapolis: Bethany House, 2003.

GOMBIS, Timothy G. A Radically New Humanity: The Function of the Haustafel in Ephesians. Journal of the Evangelical Theological Society, v. 48, 2005, p. 317-330.

GORMAN, Michael. Apostle of the Crucified Lord: A Theological Introduction to Paul \& His Letters. $2^{a}$ Edição. Grand Rapids: William B. Eerdmans, 2017.

HARDING, Mark. Disputed and Undisputed Letters of Paul. In: PORTER, Stanley (Ed.). The Pauline Canon. Boston: Brill, 2004, p. 129-168. 
HOEHNER, Harold W. Ephesians: An Exegetical Commentary. Grand Rapids, MI: Baker, 2002.

HURTADO, Larry. Destroyer of the Gods: Early Christian Distinctiveness in the Roman World. Waco: Baylor, 2016.

KITTEL, Gerhard; BROMILEY, Geoffrey W.; FRIEDRICH, Gerhard (Eds.). Theological Dictionary of the New Testament - Vol. 6. Grand Rapids: Eerdmans, 1964.

KLOHA, Jeffrey. The Problem of Paul's Letters: Loss of Authority and Meaning in the “Canonical Approach" of Brevard Childs. Concordia Journal, 2009, p. 156-169.

KÖSTENBERGER, Andreas; MERKLE, Benjamin; PLUMMER, Robert (Eds.). Going Deeper with New Testament Greek: An Intermediate Study of the Grammar and Syntax of the New Testament. Nashville: B\&H, 2016.

LARKIN, William J. Ephesians: A Handbook on the Greek Text. Waco: Baylor University Press, 2009.

LINCOLN, Andrew T. Ephesians: Word Biblical Commentary - Vol. 42. Dallas: Word Incorporated, 1990.

MACARTHUR, John; MAYHUE, Richard. Biblical Doctrine: A Systematic Summary of Bible Truth. Wheaton: Crossway, 2017.

MEADE, David G. Pseudonymity and Canon: An Investigation into the Relationship of Authorship and Authority in Jewish and Earliest Christian Tradition. Grand Rapids: Eerdmans, 1986.

MERKLE, Benjamin. The Start of Instruction to Wives and Husbands - Ephesians 5:21 or 5:22?. Bibliotheca Sacra, v. 174, 2017, p. 179-192.

MOULTON, James Hope; MILLIGAN, George. The Vocabulary of the Greek Testament. London: Hodder and Stoughton, 1930.

MYATT, Alan; FERREIRA, Franklin. Teologia Sistemática: Uma Análise Histórica, Bíblica, e Apologética para o Contexto Atual. São Paulo: Vida Nova, 2007.

NEUMANN, Kenneth J. The Authenticity of the Pauline Epistles in the Light of Stylostatistical Analysis. Atlanta: Scholars Press, 1990.

NIDA, Eugene Albert; LOUW, Johannes P. (Eds.). Greek-English Lexicon of the New Testament: Based on Semantic Domains - Vol. 1. New York: United Bible Societies, 1996.

O'DONNELL, Matthew Brook. Corpus Linguistics and the Greek of the New Testament. Sheffield: Sheffield Phoenix Press, 2005.

PAGELS, Elaine. The Interpretation of Knowledge. In: ROBINSON, James (Ed.). The Nag Hammadi Library in English. $4^{a}$ Edição. New York: Brill, 1996, p. 651-662.

PAUL, Shalom M. Exodus 21:10: A Threefold Maintenance Clause. Journal of Near Eastern Studies, v .28, 1969, p. 48-53. 
PITTS, Andrew W. Style and Pseudonymity in Pauline Scholarship: A Register Based Configuration. In: PORTER, Stanley; FEWSTER, Gregory (Eds.). Paul and Pseudepigraphy. Boston: Brill, 2013, p. 113-152.

MOLLENKOTT, Virginia Ramey. Emancipative Elements in Ephesians 5:21-33: Why Feminist Scholarship has (Often) Left Them Unmentioned, and Why They Should be Emphasized. In: LEVINE, Amy-Jill; BLICKENSTAFF, Marianne (Eds.). A Feminist Companion to Paul: Deutero-Pauline Writings. New York: T\&T Clark, 2003, p. 37-58.

RICHARDSON, Ernest Cushing. Theodoret, Jerome, Gennadius, Rufinus: Historical Writings, Etc. In: SCHAFF, Philip; WACE, Henry (Eds.). A Select Library of the Nicene and Post-Nicene Fathers of the Christian Church - Vol. 3. New York: Christian Literature Company, 1892, p. 351-354.

ROBERTSON, Archibald Thomas. A Grammar of the Greek New Testament in the Light of Historical Research. Logos Bible Software, 2006.

RUNGE, Steven E. Discourse Grammar of the Greek New Testament: A Practical Introduction for Teaching and Exegesis. Bellingham: Lexham Press, 2010.

SKINNER, Matthew L. A Companion to the New Testament: Paul and the Pauline Letters. Waco: Baylor, 2018.

SIM, Margareth G. Marking Thought and Talk in New Testament Greek: New Light From Linguistics on the Particles ?va and ?tı. Cambridge: James Clarke \& Co., 2011.

THIELMAN, Frank. Ephesians. In: BEALE, G. K.; CARSON, D. A. Commentary on the New Testament Use of the Old Testament. Grand Rapids: Baker Academic, 2007.

USTERI, Leonhard. Die Entwicklung des paulinischen Lehrbegriffs. Zürich: Orell Füssli, 1824.

WALLACE, Daniel B. Greek Grammar beyond the Basics: An Exegetical Syntax of the New Testament. Grand Rapids: Zondervan, 1996.

WESTFALL, Cynthia Long. This is a Great Metaphor! Reciprocity in the Ephesians Household Code. In: PORTER, Stanley; PITTS, Andrew (Eds.). Christian Origins and Greco-Roman Culture: Social and Literary Contexts for the New Testament. Leiden: Brill, 2013 p. 561-598.

WRIGHT, Nicholas Thomas. Paul: A Biography. San Francisco: Harper Collins, 2018. . Paul and the Faithfulness of God. Minneapolis: Fortress, 2013. . Jesus and the Victory of God. London: SPCK, 1996.

. The Climax of the Covenant: Christ and the Law in Pauline Theology. Minneapolis: Fortress, 1993.

Submetido em: 30-4-2019

Aceito em: 17-11-2019 